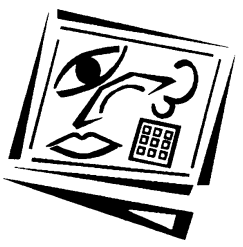

\title{
Using activity theory and its principle of contradictions to guide research in educational technology
}

\author{
Elizabeth Murphy and Maria A. Rodriguez-Manzanares \\ Memorial University of Newfoundland
}

\begin{abstract}
This paper describes how activity theory (AT) and its principle of contradictions may be relied on to guide research in educational technology. The paper begins with a theoretical overview of AT and of its principle of contradictions. It follows with a synthesis of studies that have used AT as a lens to study information and communication technologies (ICTs) in educational contexts. We analyse educational technology studies that have focused on contradictions in terms of their underlying assumptions, research questions, approaches to analysis, findings, and implications. The lens of AT and contradictions provides a versatile tool to inquire into various aspects of educational technology use, taking into account individual and institutional perspectives as well as evolution over time. AT and its principle of contradictions provide insights into how transformation may occur with use of ICTs in educational contexts.
\end{abstract}

\section{Introduction}

Activity theory (AT) has been described as "the best kept secret in academia" (Engeström, 1993, p. 64). It is a framework or descriptive tool (Nardi, 1996a) that provides "a unified account of Vygotsky's proposals on the nature and development of human behaviour" (Lantolf, 2006, p. 8). In the context of technology use, AT allows us, as Kaptelinin and Nardi (2006) have argued, to move away from a technocentric perspective, or "from the computer as the focus of interest to understanding technology as part of the larger scope of human activities" (p. 5). AT is useful as a lens to analyse the activity of an organisation that involves computer use (Kaptelinin, 1996). From an AT perspective, the computer is simply another tool mediating the interaction of humans with their environment (Bannon \& Kaptelinin, 2000). In the field of education, AT can facilitate understanding of how technological advances influence change (Bellamy, 1996). Gay, Rieger and Bennington (2001) explained that the theory "draws attention to the dialectical process by which consciousness, learning, and development simultaneously shape and are shaped by technology" (p. 509).

Contradictions constitute a key concept or principle in AT (Engeström, 2001) and are characteristic of activity systems (Engeström, 1987; Il'enkov, 1982). They are not simply conflicts or problems, but are "historically accumulating structural tensions within and between activity systems" (Engeström, 2001, p. 137). They generate "disturbances and conflicts, but also innovative attempts to change the activity" (p. 134). Activity systems are "constantly working through contradictions" and, in that sense, are "virtual disturbance- and innovation- producing machine[s]" (Center for Activity Theory and Developmental Work Research, 2003-2004, The Activity System section, II 12). As Cole and Engeström (1993) explained, in activity systems, "equilibrium is an exception and 
tensions, disturbances, and local innovations are the rule and the engine of change" (p. 8). The notion of contradictions as the driving force of change and development in activity systems has been gaining "due status as a guiding principle of empirical research" (Engeström, 2001, p. 135).

This paper describes how activity theory (AT) and its principle of contradictions may be relied on to guide research in educational technology. The paper begins with a theoretical overview of AT and of its principle of contradictions. It follows with a synthesis of studies that have used AT as a lens for studying information and communication technologies (ICTs) in educational contexts. We analyse educational technology studies that have focused on contradictions in terms of their underlying assumptions, research questions, approaches to analysis, findings, and implications.

\section{Activity theory: An overview of the theory}

AT investigates human activity, understood as activity in a specific social setting (Parks, 2000), such as work or learning. The main unit of analysis in AT is the activity system, defined as "object oriented, collective, and culturally mediated human activity" (Engeström \& Miettinen, 1999, p. 19). A model of the structure of activity system was formulated by Engeström (1987) which includes the interacting components of subject, object, tools (instruments or artefacts), division of labour, community, rules, and outcome as follows:

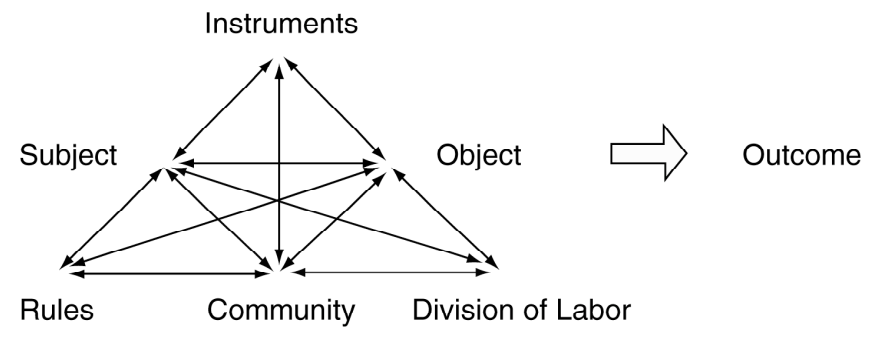

Figure 1: Components of the activity system (Engeström, 1987)

- The subject of an activity system is the individual or group whose viewpoint is adopted.

- Object "refers to the 'raw material' or 'problem space' at which the activity is directed and which is molded or transformed into outcomes with the help of physical and symbolic, external and internal tools" (Engeström, 1993, p. 67). It precedes and motivates activity.

- Tools mediate the object of activity. They can be external, material (e.g., a textbook, a computer) or internal, symbolic (e.g., language). Tools take part in the transformation of the object into an outcome, which can be desired or unexpected. They can enable or constrain activity.

- Community refers to the participants of an activity system, who share the same object.

- The division of labour involves the division of tasks and roles among members of the community and the divisions of power and status.

- Rules are explicit and implicit norms that regulate actions and interactions within the system (Engeström, 1993; Kuutti, 1996). 
The activity of learning is described by Basharina (2007), using the elements of the activity system, as "the joint activity of a learner, physical/symbolic tool(s), and another person(s) performing together as a working social system to achieve some outcome under cultural constraints such as rules" (p. 84).

Five principles of AT have been formulated by Engeström (2001):

1. According to the first principle, the main unit of analysis in AT is the activity system (Engeström, 2001).

2. Multi-voicedness refers to multiple perspectives, interests, and traditions, which can be a source of trouble and of transformation in the system, as members of an activity system "carry their own diverse histories" and the system itself "carries multiple layers and strands of history engraved in its artefacts, rules and conventions" (Engeström, 2001, p. 136).

3. The principle of historicity argues that the history of activity systems helps understand their problems as well as their potentials because "parts of older phases of activities stay often embedded in them as they develop" (Kuutti, 1996, p. 26).

4. Contradictions can result in tensions but also transformation in activity systems. In a context of education, for example, a contradiction in teachers' practices might occur when a new technology is introduced into their activity system and clashes with an old element.

5. Expansive learning relates to the possibility of expansive transformations in activity systems through reconceptualisation of the object and the motive of activity "embrac[ing] a radically wider horizon of possibilities than in the previous mode of the activity" (Engeström, 2001, p. 137).

\section{Activity theory in educational technology contexts}

The lens of AT can provide insights into change in teachers' practices or into how their teaching is "restructured" (Buell, 2004, p. 1984) when a new technological tool becomes part of their teaching activity. AT has also been relied on to study contexts of implementation of innovation in education, such as when new technology is introduced and conflicts occur between teachers' beliefs and their actual practices (e.g., Buell, n.d.; Lim \& Hang, 2003; Russell \& Schneiderheinze, 2005). AT has also been applied to studies of learners. For example, Blin (2004) investigated learners' educational histories and their histories of use of technology to help understand instances of student resistance to new tools in contexts of new uses of technology for learning. AT can help illuminate challenges related to cultures of use of tools (see Thorne, 2003) occurring when students "approach [a] new task with old habits" (Blin, 2004, p. 167). Brine and Franken (2006) relied on an AT perspective to identify challenges in online educational environments in relation to group processes and how new tools facilitate or impede these processes. AT has been used to study the design and implementation of learning supported by technology (e.g., Barab, Schatz \& Scheckler, 2004; Blin, 2004, 2005; Brine \& Franken, 2006; Issroff \& Scanlon, 2002).

AT allows for a focus at the level of individual teacher practices but also at the broader organisational level, as Benson et al. (2008) highlight in their study of online programs: "AT reveals the interfaces between e-learning at the macro (strategy, policy, 'campus wide' solutions) and the micro-organisational levels (everyday working practice, iterative change, individual adaptation)" (p. 456). AT also supports a focus on multiple interacting activity systems (e.g., Benson et al., 2008; Lim \& Hang, 2003). In an AT 
study of the integration of technology in schools, Lim and Hang found that the effective integration of technology requires a focus on activity systems beyond those of single classrooms. Buell (n.d.) argued that AT allows for a focus on the day to day classroom activity of teachers and the institutional departmental or school wide level, where the collaboration of teachers and others might result in the transformation of activity. An AT perspective on the study of integration of new technologies in education shifts from a focus on tools themselves to tool use (e.g., Benson et al., 2008), or, as Barab et al. (2004) explain, from tools' "usability" to their "sociability." In addition, as Dobson, LeBlanc and Burgoyne (2004) argued in relation to use of tools, AT considers "the roles of those involved in the system not just the most obvious user" (Discussion and Conclusion section, II 5).

\section{Contradictions: An overview of the principle}

Contradictions have been described as "a misfit within elements, between them, between different activities, or between different developmental phases of a single activity" (Kuutti, 1996, p. 34). They have also been characterised as conflicts (Dippe, 2006), as tensions (Basharina, 2007; Berge \& Fjuk, 2006) and as historically accumulating tensions (Engeström, 2001). Drawing on Wenger (1998), Barab, Barnett, Yamagata-Lynch, Squire and Keating (2002) conceptualised tensions as system dualities and used the term systemic tensions instead of contradictions. Murphy and Rodriguez-Manzanares (in press) used a general definition of contradiction as a "tension, contrast, denial, or opposition between two propositions" (Data analysis section, II 2).

Contradictions emerge as disturbances, which are visible manifestations of contradictions (Capper \& Williams, 2004) or "unintentional deviations from the script [which] cause discoordinations in interaction" and "deviations in the observable flow of interaction" (Engeström, Brown, Christopher, \& Gregory, 1991, p. 91). They are disruptions (Berge \& Fjuk, 2006), "problems, ruptures, breakdowns, clashes" in activities (Kuutti, 1996, p. 34). They result in double binds in everyday practices when an individual receives "two messages or commands which deny each other" (Engeström 1987, p. 174).

Contradictions are important, not in and of themselves, but because they can result in change and development (Engeström, 2001). Engeström and Miettinen (1999) emphasise a view of contradictions as "the motive force of change and development" (p. 9). Engeström (2001) explains how contradictions can lead to innovation and transformation in an activity system:
As the contradictions of an activity system are aggravated, some individual participants begin to question and deviate from its established norms. In some cases, this escalates into collaborative envisioning and a deliberate collective change effort. An expansive transformation is accomplished when the object and motive of the activity are reconceptualized to embrace a radically wider horizon of possibilities than in the previous mode of the activity. (p. 137)

Despite the potential of contradictions to result in transformation in an activity system, this transformation does not always occur. In fact, contradictions can either enable learning to progress, or they can actually "disable" it, depending on "whether or not they are acknowledged and resolved" (Nelson, 2002, p. 34). Additionally, in order for systemic contradictions to lead to innovation, their resolution cannot occur at the individual level "because contradictions are in social/material relations among groups 
of people and the tools they use" (Wardle, 2004, Cultural-Historical Activity Analysis section, I 4).

Contradictions may not lead readily to transformation because they may not be easily identifiable or they may not be easily acknowledged, visible, obvious, or even openly discussed by those experiencing them (Capper \& Williams, 2004; Engeström, 1993, 2001). Capper and Williams conceive of invisible or undiscussible contradictions as "the most difficult... to use as springboards for growth" (p. 12) in relation to the context of work of teams. From their perspective, an invisible contradiction is taken for granted, members of a group do not even recognise it as a difficulty, and it includes "cultural assumptions about how things are done and how relationships are managed" (p. 12). On the other hand, undiscussible contradictions are those not talked about because they are "embarrassing, uncomfortable or culturally difficult to confront," such as "gender... issues... or offensive personal habits of politically powerful program stakeholders" (p. 12).

\section{Studies of contradictions in educational technology contexts}

There have been a limited number of studies focusing on contradictions in contexts of technology use in education (e.g., Barab et al., 2002; Basharina, 2007; Berge \& Fjuk, 2006; Dippe, 2006; Fåhræus, 2004; Hardman, 2005; Murphy \& Rodriguez-Manzanares, in press; Peruski, 2003; Russell \& Schneiderheinze, 2005). Some studies were not included for analysis in this paper. These addressed contradictions in contexts where technology was present but for which the findings were not centred on contradictions as they relate to technology (e.g., Engeström, Engeström \& Suntio, 2002a; 2002b; Nelson \& Kim, 2001; Nelson, 2002). For example, Nelson and Kim's study on contradictions, which they refer to as tensions, was conducted in a context of learning second language writing skills where technology was used, but its findings on contradictions did not centre on the role of technology.

\section{Underlying assumptions, foci, and research questions}

The studies of Barab et al. (2002), Dippe (2006), Hardman (2005) and Murphy and Rodriguez-Manzanares (in press) were premised on the importance of examining change and innovation in activity systems. The examination of change is facilitated by the investigation of how contradictions are approached and resolved. For example, Dippe noted that "the success or failure of a system depends on the ability to resolve... contradictions" (p. 3). Barab et al. explained that examining the interplay of contradictions, which they refer to as system dualities or systemic tensions, can help "understand and support the continued innovation of [a] system" (p. 80). Hardman's study of a mathematics teacher's use of technology in a rural school put forth a similar argument. She argued that reliance on AT and contradictions helps to identify "dynamic forces of change" (p. 99) as well as to illustrate how transformation can be tracked. Her use of contradictions was premised on the notion that they are indicative of change as follows: "We can anticipate that the introduction of the computer as a novel tool may indeed lead to shifts in pedagogical practice" (p. 12). In a context of high school e-teachers' practices, Murphy and Rodriguez-Manzanares argued that a perspective on contradictions can help understand how contradictions may result in educational innovation in that setting.

Peruski (2003) and Russell and Schneiderheinze (2005) were interested in exploring the notion of how contradictions may not always be resolved or lead to change. For 
example, Russell and Schneiderheinze studied four teachers' implementation of technology and examined their unresolved contradictions as a barrier or challenge to meeting educational goals. For Basharina (2007), contradictions provided a lens to study cultural misunderstandings in contexts of intercultural telecollaboration. The author highlighted the importance of historicity and the need to consider participants' history of computer use. She relied on Thorne's (2003) AT work, which has investigated students' computer use relying on the concept of cultures of use of an artefact, or "the historically sedimented characteristics that accrue to a CMC [computer mediated communication] tool from its everyday use" (p. 40). Thorne demonstrated that "the learners' relationship with physical contexts and computers may facilitate contradictions" (p. 84). Therefore, analysis of contradictions in that context needs to include students' broad cultures of use of computer technologies. This focus in her study is consistent with the move from product oriented towards process oriented research centred on "the contexts of computer use and evolving interaction" (p. 82).

In a context of online meetings relying on instant messaging, Berge and Fjuk's (2006) emphasis on contradictions or "areas of tension" (p. 16) helped them focus on "moment-by-moment" (p. 16) interactions. In a study of collaboration in distance education, Fåhræus (2004) referred to the value not so much of contradictions but of AT in general as an analytical tool: "By using activity theory... as a framework for the analysis, it is possible to describe relationships between students and teachers, as well as instruments, and rules for collaboration" (p. 129). Barab et al. (2002) also referred to the value of AT explaining that it helped them gain insight into the dynamics of the activity system of a course, rather than study its components in isolation. Use of AT facilitated their analysis of change over time in that activity system, as follows: "It is not the static model, but rather the trajectory of the system through time, that makes activity theory a useful theoretical lens for characterizing activity" (p. 103). They also argued that this type of research allows for a focus on development as it is occurring, which in turn has implications for research, because researchers can contribute to the evolution of a system.

In Dippe's (2006) investigation of a distance program, the research question was formulated as follows: "What practices and contradictions for the students and the teachers emerge due to the design characteristics of the... programme?" (p. 2). Basharina's (2007) research addressed contradictions in the form of "intercultural tensions" (p. 83) and, in order to gain further insights, she also addressed the underlying reasons for contradictions. Her research questions were stated as follows: "What were the contradictions that emerged in the project under study?" and "What were the underlying reasons for those contradictions?" (p. 87). Hardman (2005) focused specifically on the capacity of contradictions to bring about change. She asked "whether the introduction of a new tool-the computer-into the classroom shift[ed] a teacher's pedagogical practice" (p. 99). Peruski's (2003) focus also included change. In relation to contradictions in the course of designing and teaching online classes, his study articulated one research question as follows: "Does participating in [design and teaching] transform the thinking of the participants or the systems on issues such as course design, teaching, learning, technology and face-to-face teaching?" (p. 28).

\section{Types of studies and data sources}

Case studies are a favoured research design in the study of contradictions in general and in contexts of technology use in particular. A focus on activity systems and contradictions is congruent with Yin's (2003) description of case study as investigating 
“a contemporary phenomenon within its real-life context" (p. 14). AT focuses on whole systems of activity; rather than considering individuals in isolation, it situates individuals within the activity system(s) in which they are involved. Additionally, as Yin explains, case study inquiry "benefits from the prior development of theoretical propositions to guide data collection and analysis" (p. 13).

Studies may rely on single (e.g., Hardman, 2005) or multiple (e.g., Russell \& Schneiderheinze, 2005) case study design. The length of the studies may vary from one semester or one course (e.g., Basharina, 2007; Berge \& Fjuk, 2006; Fåhræus, 2004) to years (e.g., Barab et al., 2002). The number of participants can also vary. For example, while Russell and Schneiderheinz's (2005) multiple case study relied on the participation of four teachers, one of two studies conducted by Dippe (2006) included survey responses of 434 students.

Data collection techniques may include individual interviews (e.g., Peruski, 2003); group interviews (e.g., Basharina, 2007); transcripts of interactions from video recordings of classes or meetings (e.g., Barab et al., 2002); chat room conferences (e.g., Russell \& Schneiderheinze, 2005); emails and online discussion forums (e.g., Basharina, 2007); instant messaging sessions (e.g., Russell \& Schneiderheinze, 2005); online journals (e.g., Russell \& Schneiderheinze, 2005); observations (e.g., Fåhræus, 2004); field notes (e.g., Barab et al., 2002); questionnaires (e.g., Dippe, 2006); documentary evidence (e.g., Barab et al., 2002); student assignments (e.g., Basharina, 2007); analysis of artefacts (e.g., Berge \& Fjuk, 2006); and recall analysis (e.g., Barab et al., 2002).

The studies considered combined various sources of data, such as interviews with class observations and documentary data. Some rely on interview data as the main data source (e.g., Murphy \& Rodriguez-Manzanares, in press; Peruski, 2003). In some instances, other techniques are used to collect data prior to interviewing, and interviewing is conducted with the specific objective of gaining further insights into contradictions. This approach is illustrated by Barab et al.'s (2002) study of activity in an astronomy course, where interviews were "targeted toward identifying student conceptual understandings" (p. 86). Another illustration is Basharina's (2007) study where the researcher collected student data, conducted content analysis of interaction data, and subsequently interviewed students and instructors, in order to explore the underlying reasons for contradictions.

Although research within an AT framework often relies on qualitative and historical methods, quantitative methods have also been used (Russell, 2001). For example, Dippe's (2006) study of contradictions combined quantitative and qualitative approaches to enquiry in a context of a distance education program for teachers. It included large scale data obtained through student questionnaires which were statistically analysed. Basharina (2007) and Fåhræus (2004) used what they referred to as ethnographic methods. Basharina argued that ethnographic methods tracking "the history and development of practice as it naturally occurs" (p. 87) fit with AT.

\section{Analysis of contradictions}

A typical approach to the analysis of contradictions involves relying on Engeström's model of AT, which depicts the elements of an activity system. This approach often involves preceding analysis with a description of the activity system in terms of its elements-subject, tools, object, outcome, division of labour, community, and rules (see Engeström, 1987). The description helps provide contextualisation, as in Fåhræus' 
(2004) portrayal of the activity system of the distance education student in the context of his study:

I have... chosen to regard the student as the subject in my analysis. The object of the student's activity is studies, and the desired outcome is to manage the studies in order to pass an exam. The instrument can be lessons, course material, a pedagogic method, and / or technology. The student belongs to a community of students, but here are also the teacher, the family and other important people. (pp. 132-133)

The model can also be used to depict contradictions in the activity systems of education professionals, such as teachers or designers, and to subsequently conduct cross-case analysis of contradictions. This approach was applied in Peruski's (2003) and Russell and Schneiderheinze's (2005) studies, which compared and contrasted educators in terms of the contradictions identified in their systems.

Analysis of contradictions using Engeström's model of AT might involve identifying contradictions in the activity system under study, such as those occurring between elements of the activity system. An example is Hardman's (2005) study of a teacher's perspective on the introduction of computers in an educational setting. Hardman presented the changing teacher and student roles in terms of a contradiction between tools and division of labour resulting from "the novelty of the tool" and "the fact that the teacher is unable to assist all students with the computer tasks" (p. 107). In other cases, researchers identify contradictions within an element of an activity system. Barab et al.'s (2002) modelling of students' activity system in a course included contradictions within elements, such as a contradiction within the subject between the students as "passive recipient" or "engaged learner" (p. 102). Finally, some studies identify contradictions resulting from activity taking place between two interacting activity systems. One illustration is Murphy and Rodriguez-Manzanares' (in press) identification of contradictions between the intersecting activity systems of the physical and virtual classroom from the perspective of high school teachers who had moved from one system to the other.

Analysing data with a focus on contradictions might involve a phase of analysis in which researchers zoom in on the analysis (see Barab et al., 2002; Basharina, 2007; Berge \& Fjuk, 2006). This process of zooming in, or conducting analysis through a more specific or narrow lens, is reflected in Barab et al.'s study, where the researchers investigated "the relations of participant and object" (p. 84) in order to identify pervasive or overall tensions in a course. The authors used the term tensions rather than contradictions. After they identified tensions in the form of themes, they conducted "more focused analyses of specific, momentary interactions during the course" (p. 85). Analysis proceeded with a focus on tensions by analysing one data source after another and using constant comparison. Another way researchers might zoom in is by conducting an initial analysis of the whole data set and then selecting specific segments of data. For example, Berge and Fjuk coded by categories and subsequently selected episodes of their interaction data for more detailed analysis.

Barab et al.'s (2002) study, which used both quantitative and qualitative data, illustrates how analysis may need to be ongoing, iterative, parallel to data collection, and involve data from additional sources. Their analysis of contradictions involved a first phase where they identified themes. They subsequently selected "various participants (students, instructor), tools, practices (tool and concept related), student productions (e.g., projects developed), and conceptual understandings (e.g., 
understandings of eclipses, instructor practices, project expectations)" and further used their database and field notes "to identify their unfolding through strings of actions throughout the course" (p. 85) in yet another phase of analysis. The need for various stages of analysis relates to the authors' articulation of their research agenda. As they explain, the study, consistent with Roth's (1996) guidelines for AT enquiry, "supported and refuted emerging hypotheses about how practices, resources, task constraints, task manifestations, and student understandings evolved over time" (Barab et al., 2002, p. 83).

Analysis from a perspective of contradictions and AT in general can be aided by specific instruments, coding techniques, and protocols. Dippe's (2006) analysis involved categorising students' questionnaire comments according to an adapted version of Jonassen and Roher-Murphy's (1999) AT scheme, which was originally designed for designing constructivist learning environments. Murphy and RodriguezManzanares (in press) created and used coding rules to identify and articulate contradictions in transcripts of interviews. For each unit of text, coding involved identifying if a contradiction was or was not present and, if present, articulating it according to coding rules. The rules for identifying if a contradiction was or was not present relied on whether it was or was not possible to identify a double bind, or two forces pulling in opposite directions (see Engeström, 1987, 1996) in the unit being coded. The rules for articulating a contradiction involved using two propositions with the same subject as well as including the actual words of the interviewee as much as possible. The following examples from two different units reflect a contradiction between prior teacher practices in the face to face classroom and the requirements of teaching online in an environment mediated by online tools:

In the face to face classroom, teachers can assess homework informally in the two minutes it takes for students to find their seats, but in the virtual classroom they have to do a formal assessment, and it takes at least 15 to 20 minutes to go through 20 or 30 submissions. (Murphy, Rodriguez-Manzanares, Dodd \& Kerr, 2006, II 17)

When teachers are face to face, they can see the students and control their attention, but, online, they can't do that, so they need to have a way to make sure students are attentive, and the only way to do that is interaction. (Murphy et al., 2006, I 14)

Once the contradictions have been coded, they can be grouped by theme or category (e.g., Basharina, 2007; Berge \& Fjuk, 2006; Dippe, 2006). Basharina coded interview transcripts for recurrence of emergent themes which were sorted and grouped.

\section{The findings of studies of contradictions}

The findings of the studies we analysed were sometimes presented and discussed in terms of contradictions occurring between elements of an activity system (e.g., Basharina, 2007; Fåhræus, 2004; Hardman, 2005; Russell \& Schneiderheinze, 2005), within an element of an activity system (e.g., Russell \& Schneiderheinze, 2005), or between interacting activity systems (e.g., Basharina, 2007; Murphy \& RodriguezManzanares, in press). Russell and Schneiderheinze used Engeström's (1987) model to present contradictions between elements in the activity system of each of four participating teachers, which they subsequently used to conduct cross-case comparison. One insight gained through this approach was that two of the teachers, who initially felt isolated from other colleagues and did not have experience collaborating with them, resolved contradictions through their participation in online interaction with colleagues. 
Barab et al. (2002) used the model to represent activity in a course from the point of view of students. They portrayed contradictions within individual elements, such as a contradiction they found in the subject (the learner) in the context of their study, in terms of passive recipient versus engaged learner. The model also portrayed contradictions between elements of the system, all of which revolved around the object of learning astronomy. The distribution of tasks between learners in one group, which was found to be "a good practice for accomplishing tasks as team" was, however, "not as successful for fostering the development of a broad understanding of astronomy" (p. 99). This was because some learners did not learn concepts that another team member had been responsible for. The authors interpreted this finding as a contradiction between the division of labour-in terms of students distributing tasks in the group versus each individual carrying out all the tasks-and the object of learning astronomy.

Findings may highlight the importance of considering the previous history of participants as users of technology as well as their beliefs and expectations related to technology use. For example, one of the intercultural contradictions in Basharina's (2007) study manifested itself as a genre clash among the groups of students of different nationalities. This clash related to the students' differing expectations about use of the discussion forum. The Mexicans accused the Russians of plagiarism, given the formal, academic nature of their postings. The author interpreted that the practice of "writing beforehand" of the Russians clashed with the other groups' preferred practice of "writing at the moment" (p. 92) in the discussion forum. Another contradiction in the study more directly linked to technology use related to the fact that students were communicating asynchronously but they expressed a preference for chat communication because of its immediacy: "They desire[d] to approximate delayed bulletin board interaction to... immediate response" (p. 94). Conducted in a context of distance education, Fåhræus' (2004) research also referred to students' preferences and expectations related to technology. Fåhræus found that the tools available to students in the medium facilitated collaboration and that students demanded a collaborative environment, which conflicted with a tradition of distance learning centred on individual study.

Dippe's (2006) study also provides an illustration of clashing expectations in a technology mediated environment. In the context of the distance education program investigated in the study, online discussions had not been designed to include specific guidelines for participation on the part of teachers or instructors. This resulted in a contradiction conceptualised as teacher presence versus teacher absence in online discussions, which Dippe elaborates on as follows:

\footnotetext{
The teachers' absence in the discussion conflicted with learners' expectations in two ways: their learning process was severely inhibited on the net and both their individual and group work was seriously impaired. Since there was no interlocutor for student questions, no discussion partner or any online guidance,... the students felt abandoned by their teacher. (p. 7)
}

Findings of studies of contradictions may emphasise changes in teachers' professional practice in contexts of technology use in education, particularly in instances of introduction of new technology. Hardman's (2005) study of a teacher's use of computers in a mathematics classroom found a shift in teacher and student roles resulting from the introduction of computers, which she discussed in terms of a contradiction between tools and the division of labour: 
The introduction of the computer as a tool has required a new division of labour due in part to the novelty of the tool but also due to the fact that the teacher is unable to assist all students with the computer tasks. Hence, students have become teachers of other students. (p. 107)

Murphy and Rodriguez-Manzanares (in press) found that some distance education high school teachers reported a change in their practices when moving to virtual, distributed classrooms that lacked physical co-presence and that involved use of new tools such as direct messaging. These characteristics of the virtual learning environment created contradictions, manifested in disturbances, but they also "allowed for new forms of practice to emerge... evident in the shift from an object of activity that focuses on centralised control to one preoccupied with distributed engagement" (Discussion section, II 5).

Peruski's (2003) study, conducted in a context of new online courses, also highlighted the possibility for change in pedagogical practices. Although the instructors in the study were very experienced teaching face to face, their first online experiences resulted in anxieties about their ability to teach; however, the contradictions they faced in this regard helped them reconceptualise their practice and even transform their face to face teaching in some ways. For example, teaching online made one instructor think about how she could recreate and transfer to her face to face classes the positive experience of interaction she found in online group discussions, in terms of students' high participation and engagement. Peruski's study differed from the others in that it was the only one that included an explicit focus on continuities in instructors' practices, rather than addressing only transformations.

Findings of some studies (e.g., Barab et al., 2002; Basharina, 2007; Peruski, 2003; Russell \& Schneiderheinze, 2005) revealed instances where contradictions were not resolved. As Peruski noted, "not all contradictions are positive and lead to growth and change" (p. 154). In her study of telecollaboration, Basharina identified intercultural contradictions surfacing during interaction. One of these related to a clash between Russian students, on the one hand, and Mexican and Japanese students, on the other, in terms of the less academic nature of discussion messages. All the intercultural tensions remained unresolved and even resulted in negative attitudes among some of the students. The author interpreted them in AT terms as follows: "These contradictions were the result of having the same task - online telecollaboration - but engagement in different activities, characterized by differences in their objects/motives and mediating tools" (p. 95).

\section{Implications of studies using contradictions}

Some authors (e.g., Basharina, 2007) highlighted the need to guide students and consider their expectations and beliefs related to technology use. Barab et al. (2002) suggested that instructors could identify contradictions in their setting and consider how these influence classroom culture and how to balance them. Similarly, Russell and Schneiderheinze (2005) pointed to the need for instructors to identify contradictions between their beliefs about teaching and their practice. In relation to distance learning in particular, Dippe (2006) suggested that the roles and responsibilities of both students and instructors need to be clear, which might involve both parties jointly outlining them. Murphy and Rodriguez-Manzanares (in press) and Peruski (2003) observed that instructors moving to technology mediated environments might need professional development opportunities to help them develop strategies to support 
learning with technology. Implications for research highlighted the need to further investigate the role of the instructor in technology mediated environments (Basharina, 2007) and the instructor skills needed for effective implementation of technological innovation (Russell \& Schneiderheinze, 2005). With reference to distance learning environments in particular, Fåhræus (2004) stated that comparative studies of contradictions might be conducted in countries with different educational cultures.

\section{Conclusions}

Engeström (1993) observed that there have been no systematic efforts in the literature to provide specific attention to the principle of contradictions as a research tool. This paper has aimed to fill this gap by analysing how studies have relied on AT in general and the principle of contradictions to bring sense and meaning to the complexities of change brought about with use of ICTs in education. As this paper has illustrated, one of the strengths or advantages of AT is how it offers a broad lens of inquiry that encompasses various aspects of the educational setting such as students' and teachers' backgrounds and perspectives, the whole institutional setting, and the evolution of the activity system over time. It is in this regard that the theory supports studies of ICT use in education "as part of the larger scope of human activities" (Kaptelinin \& Nardi, 2006, p. 5). Peruski (2003) noted, for example, that AT provides a perspective which "view[s] conflict as not so much rooted in the personalities of individuals,... but as rooted in the systems in which individuals are a part of" (p. 158). A specific focus on contradictions provides an opportunity to explain and understand how teaching practices can change when ICTs are introduced into teachers' activity system.

Frameworks other than AT can be used to investigate the introduction of technology into educational and other professional settings as well as the transformations brought about by that introduction. However, it was not in the scope of our paper to contrast AT with other frameworks (for comparison of AT with other frameworks used in technology design and technology supported learning, see Dobson et al., 2004; Halverson, 2002; Nardi, 1996b). While the lack of specific procedures associated with use of AT might be considered a limitation, it may also be seen as an advantage. The variety of foci of the studies discussed in this paper as well as their varying approaches to the study of ICTs illustrate the versatility of the theory and its applicability to a wide variety of settings, contexts, and approaches.

\section{References}

Bannon, L. \& Kaptelinin, V. (2000). From human-computer interaction to computer-mediated activity. In C. Stephanidis (Ed.), User interfaces for all: Concepts, methods, and tools (pp. 183202). Mahwah, NJ: Lawrence Erlbaum.

Barab, S., A., Barnett, M., Yamagata-Lynch, L., Squire, K. \& Keating, T. (2002). Using activity theory to understand the contradictions characterizing a technology-rich introductory astronomy course. Mind, Culture, and Activity, 9(2), 76-107.

Barab, S., Schatz, S. \& Scheckler. R. (2004). Using activity theory to conceptualize online community and using online community to conceptualize activity theory. Mind, Culture, and Activity, 11(1), 25-47.

Basharina, O. K. (2007). An activity theory perspective on student-reported contradictions in international telecollaboration. Language Learning \& Technology, 11(2), 82-103. [viewed 19 July 2007]. http:/ / llt.msu.edu/vol11num2/basharina/ default.html 
Bellamy, R. (1996). Designing educational technology: Computer-mediated change. In B. Nardi (Ed.), Context and consciousness: Activity theory and human-computer interaction (pp. 123-145). Cambridge: The MIT Press.

Benson, A., Lawler, C. \& Whitworth, A. (2008). Rules, roles and tools: Activity theory and the comparative study of e-learning. British Journal of Educational Technology, 39(3), 456-467.

Berge, O. \& Fjuk, A. (2006). Understanding the roles of online meetings in a net-based course. Journal of Computer Assisted Learning, 22(1), 13-23.

Buell, J. P. (n. d.). COWS in the classroom: Technology introduction and teacher change through the lens of activity theory. [viewed 22 July 2008] http: / / edwebsfiles.ed.uiuc.edu/meter/Documents /COWS_FollowUp.pdf

Buell, J. (2004). Learning to teach with laptops: A case study of teacher change. In C. Crawford et al. (Eds.), Proceedings of Society for Information Technology and Teacher Education International Conference 2004 (pp. 1984-1985). Chesapeake, VA: AACE.

Blin, F. (2004). CALL and the development of learner autonomy: Towards an activity-theoretical perspective. Recall, 16(2), 377-395.

Blin, F. (2005). CALL and the development of learner autonomy: An activity theoretical study. Unpublished doctoral dissertation, Institute of Educational Technology, The Open University, UK. [viewed 22 July 2008] http: / / www.dcu.ie/ blinf/BlinThesis.pdf

Brine, J. \& Franken, M. (2006). Students' perceptions of a selected aspect of a computer mediated academic writing program: An activity theory analysis. Australasian Journal of Educational Technology, 22(1), 21-38. http:/ / www.ascilite.org.au/ajet/ ajet22/ brine.html

Capper, P. \& Williams, B. (2004). Enhancing evaluation using systems concepts. American Evaluation Association. http:/ / users.actrix.co.nz/bobwill/activity.doc [viewed 2 Sep 2006, verified 3 Aug 2008]

Center for Activity Theory and Developmental Work Research (2003-2004). [viewed 5 Sep 2006, verified 3 Aug 2008] http:/ / www.edu.helsinki.fi/activity/pages/chatanddwr/activitysystem/

Cole, M. \& Engeström, Y. (1993). A cultural-historical approach to distributed cognition. In G. Salomon (Ed.), Distributed cognitions, psychological and educational considerations (pp. 1-46). Cambridge: Cambridge University Press.

Dippe, G. (2006). The missing teacher: Contradictions and conflicts in the experience of online learners. Proceedings of the Fifth International Conference on Networked Learning 2006. Lancaster: Lancaster University. [viewed 10 Mar 2006, verified 3 Aug 2008] http:/ / www.networked learningconference.org.uk/past/nlc2006/abstracts/pdfs/P38\%20Dippe.PDF

Dobson, M., LeBlanc, D. \& Burgoyne, D. (2004). Transforming tensions in learning technology design: Operationalising activity theory. Canadian Journal of Learning and Technology, 30(1). http: / / www.cjlt.ca/ content/ vol30.1/ cjlt30-1_art2.html [viewed 23 July 2008]

Engeström, Y. (1987). Learning by expanding: An activity-theoretical approach to developmental research. Helsinki: Orienta-Konsultit.

Engeström, Y. (1993). Developmental studies of work as a testbench of activity theory: The case of primary care medical practice. In S. Chaiklin \& J. Lave (Eds.), Understanding practice: Perspectives on activity and context (pp. 64-103). Cambridge: Cambridge University Press. 
Engeström, Y. (1996). Developmental work research as educational research: Looking ten years back and into the zone of proximal development. Nordisk Pedagogik, 16(3), 131-143.

Engeström, Y., \& Miettinen, R. (1999). Activity Theory and individual and social transformation. In Y. Engeström, R. Miettinen, \& R. L. Punamäki (Eds.), Perspectives on Activity Theory (pp. 19-38). Cambridge: Cambridge University Press.

Engeström, Y. (2000). Activity theory as a framework for analyzing and redesigning work. Ergonomics, 43(7), 960-974.

Engeström, Y. (2001). Expansive learning at work: Toward an activity-theoretical conceptualization. Journal of Education and Work, 14(1), 133-156.

Engeström, Y., Brown, C., Christopher, L. C. \& Gregory, J. (1991). Coordination, cooperation and communication in the courts: Expansive transitions in legal work. The Quarterly Newsletter of the Laboratory of Comparative Human Cognition, 13(4), 88-97.

Engeström, Y, Engeström, R. \& Suntio, A. (2002a). Can a school community learn to master its own future? An activity theoretical study of expansive learning among middle school teachers. In G. Wells \& G. Claxton (Eds.), Learning for life in the 21st Century: Sociocultural perspectives on the future of education (p. 211-224). Cambridge, MA: Blackwell.

Engeström, Y, Engeström, R. \& Suntio, A. (2002b). From paralyzing myths to expansive action: Building computer-supported knowledge into the curriculum from below. In Stahl, G. (Ed.), Computer support for collaborative learning: Foundations for a CSCL community (pp. 318-324). Hillsdale, NJ: Lawrence Erlbaum.

Engeström, Y. \& Miettinen, R. (1999). Introduction. In Y. Engeström, R. Miettinen \& R. L. Punamäki (Eds.), Perspectives on activity theory (pp. 1-18). Cambridge: Cambridge University Press.

Fåhræus, E. R. (2004). Distance education students moving towards collaborative learning: A field study of Australian distance education students and systems. Educational Technology $\mathcal{E}$ Society, 7(2), 129-140. http:/ / www.ifets.info/journals/7_2/16.pdf

Gay, G., Rieger, R. \& Bennington, T. (2001). Using mobile computing to enhance field study. In T. Koschmann, R. Hall, \& N. Miyake (Eds.), CSCL2: Carrying forward the conversation. Mahwah, NJ: Lawrence Erlbaum.

Halverson, C. A. (2002). Activity theory and distributed cognition: Or what does CSCW need to DO with theories? Computer Supported Cooperative Work, 11(1-2), 243-267.

Hardman, J. (2005). An exploratory case study of computer use in a primary school mathematics classroom: New technology, new pedagogy? Perspectives in Education, 23(4), 99-111.

Il'enkov, E. V. (1982). The dialectics of the abstract and the concrete in Marx's 'Capital'. Moscow: Progress.

Isssroff, K. \& Scanlon, E. (2002). Using technology in higher education: An activity theory perspective. Journal of Computer Assisted Learning, 18(1), 77-83.

Jonassen, D. H. \& Rohrer-Murphy, L. (1999). Activity theory as a framework for designing constructivist learning environments. Educational Technology Research and Development, 47(1), 62-79.

Kaptelinin, V. (1996). Computer-mediated activity: Functional organs in social and developmental contexts. In B. Nardi (Ed.), Context and consciousness: Activity theory and human-computer interaction (pp. 45-68). Cambridge: The MIT Press. 
Kaptelinin, V. \& Nardi, B. (2006). Acting with technology: Activity theory and interaction design. Cambridge, MA: MIT Press.

Kaptelinin, V., Nardi, B. \& Macaulay, C. (1999). The activity checklist: A tool for representing the "space" of context. Interactions, 6(4), 27-39.

Kuutti, K. (1996). Activity theory as a potential framework for human-computer interaction research. In B. A. Nardi (Ed.), Context and consciousness: Activity theory and human-computer interaction (pp. 17-44). Cambridge, MA: The MIT Press.

Lantolf, J. (2006). Sociocultural theory and L2: State of the art. Studies in Second Language Acquisition, 28(1), 67-109.

Lim, C. P. \& Hang, D. (2003). An activity theory approach to research of ICT integration in Singapore schools. Computers \& Education, 41(1), 49-63. http: / / www.sciencedirect.com/science/article/B6VCJ-487KGKG2/1/61bfb6537fcbee91814cff5c6f5bf537 [viewed 22 July 2008]

Murphy, E. \& Rodriguez-Manzanares, M. A. (in press). Contradictions between the virtual and physical high school classroom: A third-generation activity theory perspective. British Journal of Educational Technology. DOI: 10.1111/j.1467-8535.2007.00776.x

Murphy, E., Rodriguez-Manzanares, M. A., Dodd, C. \& Kerr, B. (2006). Using third generation activity theory and contradictions to analyse qualitative data. [viewed 25 Jan 2007, verified 11 Aug 2008] http: / / cider.athabascau.ca/CIDERSessions/sessionarchive/

Nardi, B. (Ed.) (1996a). Context and consciousness: Activity theory and human-computer interaction. Cambridge, MA: MIT Press.

Nardi, B. (1996b). Studying context: A comparison of activity theory, situated action models, and distributed cognition. In B. Nardi (Ed.), Context and consciousness: Activity theory and humancomputer interaction (pp. 35-52). Cambridge, MA: MIT Press.

Nelson, C. \& Kim, M. K. (2001). Contradictions, appropriation and transformation: An activity theory approach to L2 writing and classroom practice. Texas Papers for Foreign Language Education, 6(1), 37-62.

Nelson, C. (2002). Contradictions in learning to write in a second language classroom: Insights from radical constructivism, activity theory, and complexity theory. Unpublished doctoral dissertation, The University of Texas at Austin. http:/ / www.kean.edu/ cnelson/ contradictions.pdf

Parks, S. (2000). Same task, different activities: Issues of investment, identity and use of strategy. TESL Canada Journal, 17(2), 64-88.

Peruski, L. (2003). Contradictions, disturbances, and transformations: An activity theoretical analysis of three faculty members' experience with designing and teaching online courses. Unpublished doctoral dissertation, Michigan State University.

Roth, W-M. (1996). Knowledge diffusion in a grade 4-5 classroom during a unit on civil engineering: An analysis of a classroom community in terms of its changing resources and practices. Cognition and Instruction, 14(2), 179-220.

Roth, W-M. \& Tobin, K. (2002). Redesigning an "urban" teacher education program: An activity theory perspective. Mind, Culture, and Activity, 9(2), 108-131.

Russell, D. (2001). Looking beyond the interface: Activity theory and distributed learning. In M. Lea \& K. Nicoll (Eds.), Distributed learning (pp. 64-82). New York: Routledge Falmer. 
Russell, D. L. \& Schneiderheinze, A. (2005). Understanding innovation in education using activity theory. Educational Technology E Society, 8(1), 38-53.

http: / / www.ifets.info / others / download_pdf.php?j_id=26\&a_id=520

Thorne, S. (2003). Artifacts and cultures-of-use in intercultural communication. Language Learning \& Technology, 7(2), 38-67. http:/ / llt.msu.edu/vol7num2/thorne/

Wardle, E. A. (2004). Can cross-disciplinary links help us teach "academic discourse" in FYC? Across the Disciplines, 1. http:/ / wac.colostate.edu/atd/articles/wardle2004/ [viewed 25 July 2007, verified 11 Aug 2008]

Wenger, E. (1998). Communities of practice: Learning, meaning, and identity. Cambridge, MA: Cambridge University Press.

Yin, R. K. (2003). Case study research: Design and methods (3rd ed.). Thousand Oaks, CA: Sage Publications.

Elizabeth Murphy, Associate Professor, Faculty of Education, Memorial University of Newfoundland, St. John's, NL, A1B 3X8 Canada. Email: emurphy@mun.ca. Website: http:/ / www.ucs.mun.ca/ emurphy/

Elizabeth holds a PhD in Educational Technology. Her program of research focuses on teacher practices in technology mediated contexts. She is currently principal investigator on a Social Sciences and Humanities Research Council of Canada (SSHRC) Standard Research Grant, principal investigator on a SSHRC Strategic Joint Initiative, and co-investigator on a SSHRC Community University Research Alliance.

Maria A. Rodriguez-Manzanares, Doctoral Candidate, Faculty of Education, Memorial University of Newfoundland, St. John's, NL, A1B 3X8 Canada. Email: mariar@mun.ca. Website: http:/ / mariarodriguez98.googlepages.com/

Maria is a doctoral candidate in the Faculty of Education at Memorial University of Newfoundland, Canada, and a Spanish lecturer in the Department of French and Spanish and Faculty of Education. Her areas of interest include second and foreign language learning, technology enhanced language learning, and international students. 